\title{
Development of a multiplexed bead-based immunoassay for the simultaneous detection of antibodies to 17 pneumococcal proteins
}

\author{
S. Shoma • N. J. Verkaik • C. P. de Vogel • P. W. M. Hermans • S. van Selm • \\ T. J. Mitchell • M. van Roosmalen • S. Hossain • M. Rahman • H. Ph. Endtz • \\ W. J. B. van Wamel • A. van Belkum
}

Received: 18 October 2010 /Accepted: 25 October 2010 /Published online: 18 November 2010

(C) The Author(s) 2010. This article is published with open access at Springerlink.com

\begin{abstract}
Presently, several pneumococcal proteins are being evaluated as potential vaccine candidates. Here, we gather novel insights in the immunogenicity of PLY, PsaA, PspA, PspC, NanA, Hyl, PpmA, SlrA, Eno, IgA1-protease, PdBD, BVH-3, SP1003, SP1633, SP1651, SP0189 and SP0376. We developed a multiplex bead-based immunoassay (xMAP $^{\circledR}$ Technology, Luminex Corporation) to simultaneously quantify antibodies against these 17 pneumococcal proteins in serum. The median fluorescence intensity (MFI) values obtained for human pooled serum with the multiplex assay were between $82 \%$ and $111 \%$ (median $94 \%$ ) of those obtained with the singleplex assays. For
\end{abstract}

Shereen Shoma and Nelianne J. Verkaik equally contributed to this paper.

S. Shoma $\cdot$ S. Hossain $\cdot$ M. Rahman $\cdot$ H. P. Endtz International Centre for Diarrhoeal Disease Research, Dhaka, Bangladesh

N. J. Verkaik $(\bowtie) \cdot$ C. P. de Vogel $\cdot$ H. P. Endtz

W. J. B. van Wamel · A. van Belkum

Department of Medical Microbiology and Infectious Diseases,

Erasmus Medical Center,

Rotterdam, The Netherlands

e-mail: n.j.verkaik@erasmusmc.nl

P. W. M. Hermans $\cdot$ S. van Selm

Department of Pediatrics,

Radboud University Nijmegen Medical Center,

Nijmegen, The Netherlands

T. J. Mitchell

Division of Infection and Immunity, University of Glasgow,

Glasgow G12 8TA Scotland, UK

M. van Roosmalen

Mucosis B.V.,

Groningen, The Netherlands
$\mathrm{IgG}$, the coefficient of variation $(\mathrm{CV})$ in serum ranged from $2 \%$ to $9 \%$, for $\mathrm{IgA}$, the $\mathrm{CV}$ ranged from $3 \%$ to $14 \%$ and for IgM, the CV ranged from $11 \%$ to $15 \%$. Using this immunoassay, we showed that anti-pneumococcal antibody levels exhibited extensive inter-individual variability in young children suffering from invasive pneumococcal disease. All proteins, including the proteins with, as yet, unknown function, were immunogenic. In conclusion, the multiplex Streptococcus pneumoniae immunoassay based on proteins is reproducible. This assay can be used to monitor anti-S. pneumoniae antibody responses in a material- and time-saving manner.

\section{Introduction}

Streptococcus pneumoniae (S. pneumoniae, pneumococcus) is an important human pathogen that causes life-threatening diseases such as pneumonia and meningitis, as well as less serious but highly prevalent diseases such as otitis media and sinusitis. Between 2002 and 2003, pneumonia accounted for $19 \%$ of the 10.6 million deaths per annum among children younger than 5 years of age [1]. Ninety percent of childhood deaths occurred in developing countries [2], including Bangladesh [3, 4]. The global incidence of pneumococcal meningitis in children is 17 cases per 100,000 . The case-fatality rate (CFR) for pneumococcal meningitis is high. In 2000, the global pneumococcal meningitis CFR was 59\%, ranging from $29 \%$ in the Western Pacific to $73 \%$ in Africa [5].

Fortunately, the availability of the 23-valent capsular polysaccharide and 7-valent pneumococcal conjugate vaccines (PCV23 and PCV7, respectively) has resulted in a dramatic reduction in the morbidity and mortality of 
pneumococcal diseases. However, the high costs and still limited vaccine-mediated protection, which is restricted to the included serotypes, have prevented its implementation in large-scale immunisation programmes in developing countries. For these reasons, there is considerable interest in designing alternative and more cost-effective strategies. Presently, several pneumococcal proteins are being evaluated as potential vaccine candidates. Optimally, these would provide protection against pneumococcal infection regardless of serotype [6]. To date, the most promising protein vaccine candidates include pneumolysin (PLY), pneumococcal surface adhesin A (PsaA), pneumococcal surface protein A (PspA) and pneumococcal surface protein C (PspC) [7]. These proteins are produced by virtually all clinical isolates of the pneumococcus. PLY is a $53-\mathrm{kDa}$ protein that causes cytolysis, induces complement activation and the production of cytokines and nitric oxide [8-12]. In addition, PLY has been assigned several functions with respect to modification of the immune response. PLY has recently been shown to interact with Toll-like receptor 4 (TLR-4) [13]. PsaA is a surface-exposed 37-kDa lipoprotein that plays a major role in pneumococcal attachment to the host cell and virulence [14]. PspA is a choline-binding surface protein which inhibits complement-mediated phagocytosis, binds to lactoferrin and, as such, prevents lactoferrin-mediated killing [15]. Antibodies to pneumococcal proteins PspA, PsaA and PLY have been shown to develop early in life $[16,17]$. PspC (also known as CbpA or SpsA) acts as an adhesin and binds the complement regulatory protein factor $\mathrm{H}$, to provide resistance to complement $[13,18]$.

We developed a multiplex bead-based immunoassay using Luminex xMAP ${ }^{\circledR}$ Technology to gather novel insights into the immunogenicity of PLY, PsaA, PspA and PspC and 13 other pneumococcal proteins. With this assay, antibodies to these 17 pneumococcal proteins can be quantified simultaneously. Thus far, for the pneumococcus, this technology was only used for the measurement of antibodies directed to different pneumococcal capsular polysaccharides [19-21].

\section{Materials and methods}

\section{Antigens}

The pneumococcal proteins PLY, PsaA, PspA, PspC, neuraminidase A (NanA), hyaluronidase (Hyl), putative proteinase maturation protein $\mathrm{A}(\mathrm{PpmA})$, streptococcal lipoprotein rotamase A (SlrA), $\alpha$-enolase (Eno), immunoglobulin A1 protease (IgA1-protease), PdBD and BVH-3, SP1003, SP1633, SP1651, SP0189, and SP0376 were used. NanA plays an important role in biofilm formation and promotes pneumococcal brain endothelial cell invasion [22, 23]. Hyl is present on the majority of strains. The enzyme degrades essential components of the host's extracellular matrix and, as such, it may facilitate bacterial spread in host tissues [13, 24]. PpmA and SlrA, two surface-exposed lipoproteins, have been shown to play a role in virulence and colonisation $[25,26]$. Eno has been identified both in the cytoplasm and on the surface of pneumococci and is involved in virulence by the activation of plasmin into plasminogen, a host collagen-degrading enzyme [27]. IgA1-protease plays an important role in pneumococcal colonisation. IgA1-protease modifies IgA1 antibodies so that it promotes rather than inhibits pneumococcal adherence to epithelial cells in a model of colonisation [28]. PdBD is a mutant version of PLY with less cytolytic activity and reduced ability to activate complement [29]. BVH-3 is capable of conferring protection against lethal experimental S. pneumoniae infection. This protein family was also designated Pht (for pneumococcal histidine triad) [30, 31]. SP1003, SP1633, SP1651, SP0189 and SP0376 are pneumococcal proteins with currently unknown functions. Recently, a comprehensive review summarising the surface-exposed virulence factors and their functions was published [13].

The genes encoding the proteins NanA, PsaA, PspA, PspC, SP1633, SP1651, SP0189, SP0376, Hyl, PLY and PpmA were isolated from $S$. pneumoniae strain TIGR4 chromosomal DNA and cloned in the vector pOPINF using In-Fusion Technology. Cell extracts were made from the recombinant Escherichia coli (Rosetta) strains and the recombinant proteins purified by immobilised metal affinity chromatography using the poly-His tag added to the N-terminal end of the protein during the cloning procedure. The genes used for the production of the recombinant antigens Eno, SlrA and PpmA were amplified by polymerase chain reaction (PCR) from $S$. pneumoniae D39. IgA1-protease was amplified from $S$. pneumoniae TIGR4. The amplified DNA was cloned into a pET11a expression vector (Stratagene) and electrotransformed into E. coli BL21(DE3). The expression of recombinant protein was induced by the addition of isopropyl- $\beta$-D-thio-galactoside (IPTG) and the recombinant proteins were purified by $\mathrm{Ni}^{+}$affinity chromatography, as described previously $[16,25,32]$. The genes encoding BVH-3 and PdBD were cloned into plasmid pPA195 and pPA180, respectively, and transformed into Lactococcus lactis PA1001. The overexpression of BVH-3 and PdBD was induced by nisin, essentially as described previously [33]. The purity of the recombinant proteins was determined by sodium dodecyl sulfate polyacrylamide gel electrophoresis (SDS-PAGE). The amino acid sequence of the proteins was confirmed with mass spectrometry (Ultraflex MALDI-ToF, Bruker Daltonics). 


\section{Coupling methods}

To quantify antibodies directed against the 17 S. pneumoniae proteins simultaneously, the bead-based flow cytometry technique (xMAP ${ }^{\circledR}$, Luminex Corporation) was applied. The purified proteins were coupled to fluorescent SeroMAP beads. The coupling procedure was performed as described elsewhere $[34,35]$. In each experiment, control beads were included to determine non-specific binding. For control beads, the coupling procedure was followed, except that no $S$. pneumoniae protein was added. In case of non-specific binding, the median fluorescence intensity (MFI) values were subtracted from the antigen-specific results. As a negative control, PBS-BN was included. Human pooled serum was used as a standard.

\section{Multiplex S. pneumoniae antibody assay}

The multiplex assay (serum incubated with the different fluorescence-coloured antigen-coupled beads mixed in one well) was validated by comparing the MFI values for HPS obtained with this multiplex assay with the results for HPS obtained with singleplex assays (serum incubated with individual single-colour antigen-coupled beads in separate wells). After validation, the different antigen-coupled microspheres were mixed to a working concentration of 4,000 beads per colour per well. The procedure used was the same as that described elsewhere [34-36]. To optimise dilutions, the serum samples of children were diluted 1:25, 1:50 and 1:100 in PBS-BN. The secondary antibodies were diluted 1:50, 1:100 and 1:200 in PBS-BN. Checkerboard titrations were performed. Considering the results of the MFI values and the amounts of serum and secondary antibody needed, optimal serum dilutions were 1:100 for the measurement of $\mathrm{IgG}$ and 1:50 for the measurement of antigen-specific IgA and IgM. The optimal secondary antibody dilutions were 1:200 for IgG and 1:100 for IgA and IgM. Measurements were performed on the Luminex 100 instrument (BMD) using Luminex IS software (version 2.2). Tests were performed in duplicate, and the MFI values, reflecting semi-quantitative antibody levels, were averaged.

\section{Anti-pneumococcal antibodies}

The multiplexed immunoassay was used to compare differences in anti-pneumococcal antibodies in the serum samples obtained from 54 children under the age of 5 years with clinical suspicion of pneumonia $(n=26)$ or meningitis $(n=28)$. Half of these children suffered from pneumonia/ meningitis caused by $S$. pneumoniae and the other half suffered from pneumonia/meningitis caused by a bacterial species other than $S$. pneumoniae. The serum samples were stored at $-80^{\circ} \mathrm{C}$ until use. The research protocol was approved by the Research Review and Research Ethical Committee of ICDDR,B and written informed consent from the parents was obtained.

\section{Statistical analysis}

The Mann-Whitney $U$-test was used to compare differences in the anti-pneumococcal antibody levels. Differences were considered to be statistically significant when the two-sided $p$-values were $<0.05$.

\section{Results and discussion}

Validation of the multiplex assay and reproducibility

The MFI values obtained for HPS with the multiplex assay were between $82 \%$ and $111 \%$ (median $94 \%$ ) of those obtained with the singleplex assays. Therefore, it was considered to be legitimate to use the multiplex assay. Serum incubated with control beads resulted in median MFI values for $\operatorname{IgG}, \operatorname{IgA}$ and $\operatorname{IgM}$ of 77 (range, 21-7,210), 92 (range, 15-11,549) and 1,282 (range, 171-7966), respectively. This indicates that there was quite a variable level of non-specific binding that was consistently subtracted from the antigen-specific results. The negative control (PBS-BN) incubated with protein-coupled beads resulted in low MFI values $(<10)$. Inter-assay variation was calculated from the MFI values obtained from serum samples $(n=54)$ run in two separate assays and averaged per protein and antibody isotype. For IgG, the median coefficient of variation (CV) was $5 \%$, range $2 \%$ (PsaA) to $9 \%$ (SlrA). For $\operatorname{IgA}$, the median $\mathrm{CV}$ was $7 \%$, range $3 \%$ (PspC and PsaA) to $14 \%$ (SlrA). For IgM, the median CV was $13 \%$, range $11 \%$ (SP1633) to 15\% (PspC, PpmA and PspA). Earlier studies found equal $\mathrm{CVs}$ for inter-assay variation using other types of antigens [20,34,37]. Therefore, this new multiplexed anti-pneumococcal immunoassay is considered to be reproducible from experiment to experiment.

Anti-pneumococcal antibodies

Anti-pneumococcal antibody levels showed extensive interindividual variability (Fig. 1), probably due to the variable number of previous encounters with different $S$. pneumoniae strains (colonisation, subclinical infection), as well as interindividual differences in the ability to mount a humoral immune response. The levels of IgM were not significantly different between children suffering from a pneumonia/ meningitis caused by $S$. pneumoniae or by a different bacterial species. The levels of $\operatorname{IgG}$ directed against NanA and the levels of IgA directed against $\mathrm{Hyl}$ and PpmA were higher in children suffering from a pneumonia caused by $S$. 

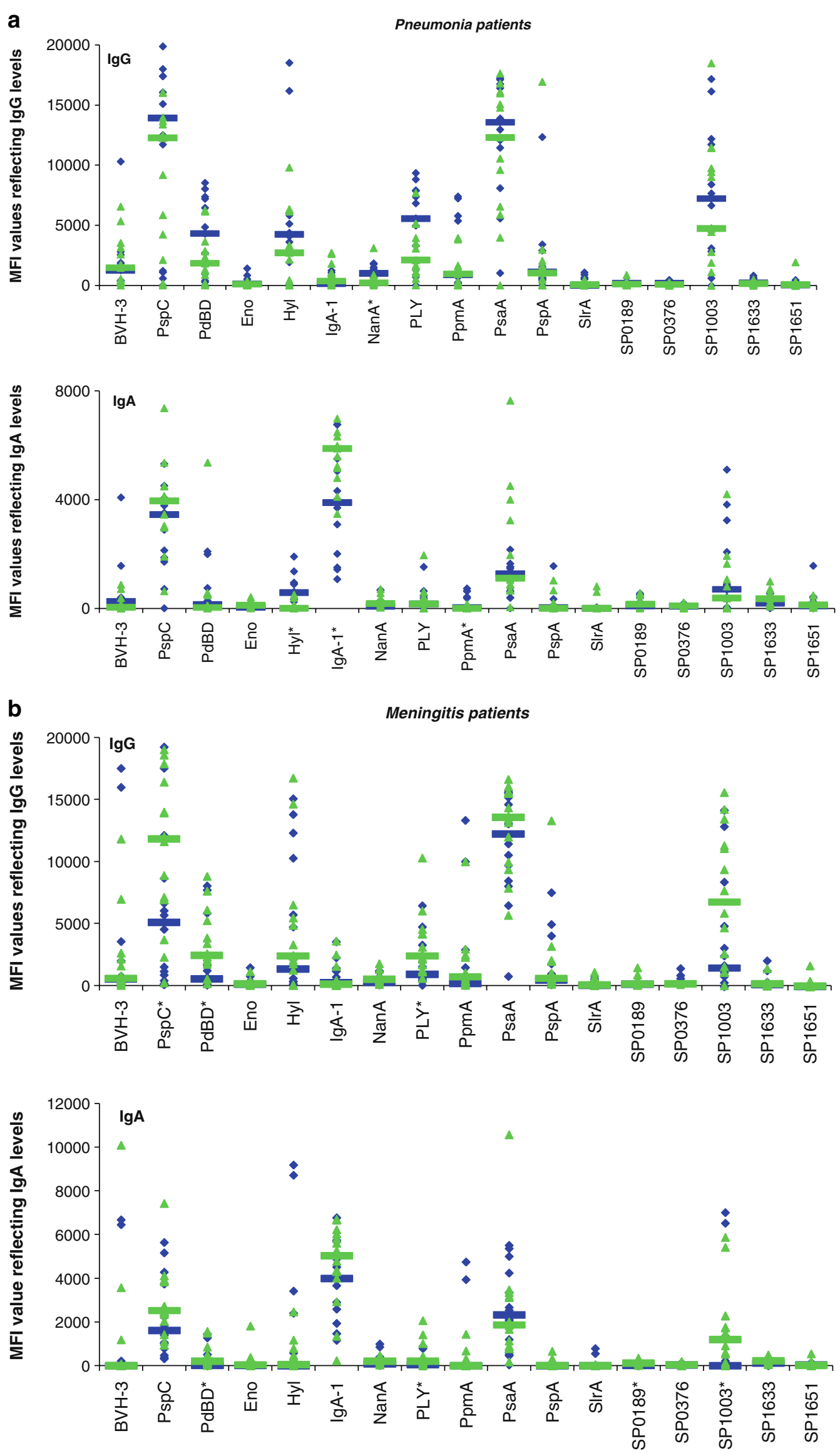
Fig. 1 Median fluorescence intensity (MFI) values reflecting levels of antigen-specific IgG and IgA for 17 Streptococcus pneumoniae antigens in the serum samples of pneumonia (a) and meningitis patients (b). The blue diamonds represent pneumonia/meningitis patients caused by $S$. pneumoniae and the green triangles represent pneumonia/meningitis patients that are positive for bacterial species other than $S$. pneumoniae. The horizontal bars indicate the median levels of anti-pneumococcal antibodies for these two groups. The asterisks indicate significant differences

pneumoniae than in children suffering from a pneumonia caused by other bacterial pathogens $(p<0.05$, Fig. 1a). In contrast, significantly higher levels of antibodies directed against IgA1-protease were detected in the serum samples of patients suffering from a non-S. pneumoniae pneumonia. This might be explained by the fact that IgA1-protease is also present in Haemophilus influenzae [38], another frequent cause of pneumonia in non-vaccinated children. In meningitis patients, the levels of IgG directed against PspC, PdBD and PLY were significantly higher in children suffering from meningitis caused by a bacterial pathogen other than $S$. pneumoniae ( $p<0.05$, Fig. 1b). Furthermore, the levels of IgA directed to PdBD, PLY, SP0189 and SP1003 were higher in this group $(p<0.05)$. We speculate that the lower $S$. pneumoniae antibody levels in the children suffering from $S$. pneumoniae meningitis might be due to the consumption of antibodies. However, such data can be obscured by the fact that we do not know the exact patient delay (time between the onset of disease and the arrival in the hospital and the collection of serum). Furthermore, the sera from children of different ages were included.

In conclusion, using our novel non-polysaccharide-based high-throughput immunological test, we were able to determine the level of antibodies to 17 pneumococcal proteins simultaneously in small-volume serum samples. The requirement for small sample volumes only is a great advantage as compared to enzyme-linked immunosorbent assay (ELISA), especially when limited amounts of samples are available, which is usually the case in young children. Novel antigens can be easily included and combinations of protein and polysaccharide antigens may help in profiling the complete immune response of both patients and healthy individuals to a common opportunistic pathogen, which is especially relevant in children in developing countries.

Open Access This article is distributed under the terms of the Creative Commons Attribution Noncommercial License which permits any noncommercial use, distribution, and reproduction in any medium, provided the original author(s) and source are credited.

\section{References}

1. Bryce J, Boschi-Pinto C, Shibuya K, Black RE; WHO Child Health Epidemiology Reference Group (2005) WHO estimates of the causes of death in children. Lancet 365:1147-1152
2. Williams BG, Gouws E, Boschi-Pinto C, Bryce J, Dye C (2002) Estimates of world-wide distribution of child deaths from acute respiratory infections. Lancet Infect Dis 2:25-32

3. El Arifeen S, Akhter T, Chowdhury HR, Rahman KM, Chowdhury EK, Alam N et al (2005) Causes of death in children under five years of age. Chapter 09 of the Bangladesh Demographic and Health Surveys, 2004 final report. National Institute of Population Research and Training, Dhaka, pp 125-133

4. Baqui AH, Sabir AA, Begum N, Arifeen SE, Mitra SN, Black RE (2001) Causes of childhood deaths in Bangladesh: an update. Acta Paediatr 90:682-690

5. O'Brien KL, Wolfson LJ, Watt JP, Henkle E, Deloria-Knoll M, McCall N et al (2009) Burden of disease caused by Streptococcus pneumoniae in children younger than 5 years: global estimates. Lancet 374:893-902

6. Black S, Shinefield H, Fireman B, Lewis E, Ray P, Hansen JR et al (2000) Efficacy, safety and immunogenicity of heptavalent pneumococcal conjugate vaccine in children. Northern California Kaiser Permanente Vaccine Study Center Group. Pediatr Infect Dis J 19:187-195

7. Simell B, Ahokas P, Lahdenkari M, Poolman J, Henckaerts I, Kilpi TM et al (2009) Pneumococcal carriage and acute otitis media induce serum antibodies to pneumococcal surface proteins CbpA and PhtD in children. Vaccine 27:4615-4621

8. Berry AM, Ogunniyi AD, Miller DC, Paton JC (1999) Comparative virulence of Streptococcus pneumoniae strains with insertionduplication, point, and deletion mutations in the pneumolysin gene. Infect Immun 67:981-985

9. Braun JS, Novak R, Gao G, Murray PJ, Shenep JL (1999) Pneumolysin, a protein toxin of Streptococcus pneumoniae, induces nitric oxide production from macrophages. Infect Immun 67:3750-3756

10. Jedrzejas MJ (2001) Pneumococcal virulence factors: structure and function. Microbiol Mol Biol Rev 65:187-207

11. Mitchell TJ, Andrew PW, Saunders FK, Smith AN, Boulnois GJ (1991) Complement activation and antibody binding by pneumolysin via a region of the toxin homologous to a human acute-phase protein. Mol Microbiol 5:1883-1888

12. Paton JC (1996) The contribution of pneumolysin to the pathogenicity of Streptococcus pneumoniae. Trends Microbiol 4:103-106

13. Mitchell AM, Mitchell TJ (2010) Streptococcus pneumoniae: virulence factors and variation. Clin Microbiol Infect 16:411-418

14. Rajam G, Anderton JM, Carlone GM, Sampson JS, Ades EW (2008) Pneumococcal surface adhesin A (PsaA): a review. Crit Rev Microbiol 34:131-142

15. Hammerschmidt S, Bethe G, Remane PH, Chhatwal GS (1999) Identification of pneumococcal surface protein A as a lactoferrinbinding protein of Streptococcus pneumoniae. Infect Immun 67:1683-1687

16. Adrian PV, Bogaert D, Oprins M, Rapola S, Lahdenkari M, Kilpi $\mathrm{T}$ et al (2004) Development of antibodies against pneumococcal proteins alpha-enolase, immunoglobulin A1 protease, streptococcal lipoprotein rotamase $\mathrm{A}$, and putative proteinase maturation protein A in relation to pneumococcal carriage and otitis media. Vaccine 22:2737-2742

17. Rapola S, Jäntti V, Haikala R, Syrjänen R, Carlone GM, Sampson JS et al (2000) Natural development of antibodies to pneumococcal surface protein A, pneumococcal surface adhesin A, and pneumolysin in relation to pneumococcal carriage and acute otitis media. J Infect Dis 182:1146-1152

18. Dave S, Brooks-Walter A, Pangburn MK, McDaniel LS (2001) PspC, a pneumococcal surface protein, binds human factor $\mathrm{H}$. Infect Immun 69:3435-3437

19. Biagini RE, Schlottmann SA, Sammons DL, Smith JP, Snawder JC, Striley CA et al (2003) Method for simultaneous measurement 
of antibodies to 23 pneumococcal capsular polysaccharides. Clin Diagn Lab Immunol 10:744-750

20. Lal G, Balmer P, Stanford E, Martin S, Warrington R, Borrow R (2005) Development and validation of a nonaplex assay for the simultaneous quantitation of antibodies to nine Streptococcus pneumoniae serotypes. J Immunol Methods 296:135-147

21. Pickering JW, Martins TB, Greer RW, Schroder MC, Astill ME, Litwin CM et al (2002) A multiplexed fluorescent microsphere immunoassay for antibodies to pneumococcal capsular polysaccharides. Am J Clin Pathol 117:589-596

22. Trappetti C, Kadioglu A, Carter M, Hayre J, Iannelli F, Pozzi G et al (2009) Sialic acid: a preventable signal for pneumococcal biofilm formation, colonization, and invasion of the host. J Infect Dis 199:1497-1505

23. Uchiyama S, Carlin AF, Khosravi A, Weiman S, Banerjee A, Quach D et al (2009) The surface-anchored NanA protein promotes pneumococcal brain endothelial cell invasion. J Exp Med 206:1845-1852

24. Humphrey JH (1948) Hyaluronidase production by pneumococci. J Pathol Bacteriol 55:273-275

25. Hermans PW, Adrian PV, Albert C, Estevão S, Hoogenboezem T, Luijendijk IH et al (2006) The streptococcal lipoprotein rotamase A (SlrA) is a functional peptidyl-prolyl isomerase involved in pneumococcal colonization. J Biol Chem 281:968-976

26. Cron LE, Bootsma HJ, Noske N, Burghout P, Hammerschmidt S, Hermans PW (2009) Surface-associated lipoprotein PpmA of Streptococcus pneumoniae is involved in colonization in a strainspecific manner. Microbiology 155:2401-2410

27. Bergmann S, Rohde M, Chhatwal GS, Hammerschmidt S (2001) alpha-Enolase of Streptococcus pneumoniae is a plasmin(ogen)binding protein displayed on the bacterial cell surface. Mol Microbiol 40:1273-1287

28. Weiser JN, Bae D, Fasching C, Scamurra RW, Ratner AJ, Janoff EN (2003) Antibody-enhanced pneumococcal adherence requires IgA1 protease. Proc Natl Acad Sci USA 100:4215-4220

29. Rijneveld AW, van den Dobbelsteen GP, Florquin S, Standiford TJ, Speelman P, van Alphen L et al (2002) Roles of interleukin-6 and macrophage inflammatory protein-2 in pneumolysin-induced lung inflammation in mice. J Infect Dis 185:123-126

30. Adamou JE, Heinrichs JH, Erwin AL, Walsh W, Gayle T, Dormitzer $\mathrm{M}$ et al (2001) Identification and characterization of a novel family of pneumococcal proteins that are protective against sepsis. Infect Immun 69:949-958

31. Hamel J, Charland N, Pineau I, Ouellet C, Rioux S, Martin D et al (2004) Prevention of pneumococcal disease in mice immunized with conserved surface-accessible proteins. Infect Immun 72:2659-2670

32. McCool TL, Cate TR, Tuomanen EI, Adrian P, Mitchell TJ, Weiser JN (2003) Serum immunoglobulin G response to candidate vaccine antigens during experimental human pneumococcal colonization. Infect Immun 71:5724-5732

33. van Roosmalen ML, Kanninga R, El Khattabi M, Neef J, Audouy S, Bosma T et al (2006) Mucosal vaccine delivery of antigens tightly bound to an adjuvant particle made from food-grade bacteria. Methods 38:144-149

34. Verkaik NJ, Brouwer E, Hooijkaas H, van Belkum A, van Wamel W (2008) Comparison of carboxylated and Penta-His microspheres for semi-quantitative measurement of antibody responses to His-tagged proteins. J Immunol Methods 335:121-125

35. Verkaik NJ, de Vogel CP, Boelens HA, Grumann D, Hoogenboezem T, Vink C et al (2009) Anti-staphylococcal humoral immune response in persistent nasal carriers and noncarriers of Staphylococcus aureus. J Infect Dis 199:625-632

36. Verkaik NJ, Lebon A, de Vogel CP, Hooijkaas H, Verbrugh HA, Jaddoe VW et al (2010) Induction of antibodies by Staphylococcus aureus nasal colonization in young children. Clin Microbiol Infect 16:1312-1317

37. Ray CA, Bowsher RR, Smith WC, Devanarayan V, Willey MB, Brandt JT et al (2005) Development, validation, and implementation of a multiplex immunoassay for the simultaneous determination of five cytokines in human serum. J Pharm Biomed Anal 36:1037-1044

38. Kilian M, Thomsen B (1983) Antigenic heterogeneity of immunoglobulin A1 proteases from encapsulated and nonencapsulated Haemophilus influenzae. Infect Immun 42:126-132 